\title{
SNP analysis of the inter-alpha-trypsin inhibitor family heavy chain-related protein (IHRP) gene by a fluorescence-adapted SSCP method
}

\author{
Teruaki Tozaki*1,2, Nam-Ho Choi-Miura' ${ }^{1}$, Matsuo Taniyama ${ }^{3}$, \\ Masahiko Kurosawa ${ }^{2}$ and Motowo Tomita ${ }^{1}$
}

Address: ${ }^{1}$ Department of Physiological Chemistry, School of Pharmaceutical Sciences, Showa University, 1-5-8 Hatanodai, Shinagawa, Tokyo 1428555, Japan, ${ }^{2}$ Department of Molecular Genetics, Laboratory of Racing Chemistry, 1731-2 Tsurutamachi, Utsunomiya, Tochigi 320-0851, Japan and ${ }^{3}$ Department of Internal Medicine, Showa University Fujigaoka Hospital, 1-30 Fujigaoka, Aoba, Yokohama, Kanagawa 227-8501, Japan

E-mail: Teruaki Tozaki* - ttozaki@nyc.odn.ne.jp; Nam-Ho Choi-Miura - nammiura@pharm.showa-u.ac.jp; Matsuo Taniyama - taniyama@showa-university-fujigaoka.gr.jp; Masahiko Kurosawa - m-kurosawa@lrc.or.jp; Motowo Tomita - tomitam@pharm.showa-u.ac.jp

${ }^{*}$ Corresponding author

Published: 29 July 2002

BMC Medical Genetics 2002, 3:6

This article is available from: http://www.biomedcentral.com//47/-2350/3/6 in all media for any non-commercial purpose, provided this notice is preserved along with the article's original URL.

Received: 20 May 2002

Accepted: 29 July 2002

\begin{abstract}
Background: Single-nucleotide polymorphisms (SNPs) are considered to be useful polymorphic markers for genetic studies of polygenic traits. Single-stranded conformational polymorphism (SSCP) analysis has been widely applied to detect SNPs, including point mutations in cancer and congenital diseases. In this study, we describe an application of the fluorescent labeling of PCR fragments using a fluorescent-adapted primer for SSCP analysis as a novel method.

Methods: Single-nucleotide polymorphisms (SNPs) of the inter-alpha-trypsin inhibitor family heavy chain-related protein (IHRP) gene were analyzed using a fluorescence-adapted SSCP method. The method was constructed from two procedures: I) a fluorescent labeling reaction of PCR fragments using fluorescence-adapted primers in a single tube, and 2) electrophoresis on a non-denaturing polyacrylamide gel.

Results: This method was more economical and convenient than the single-stranded conformational polymorphism (SSCP) methods previously reported in the detection of the labeled fragments obtained. In this study, eight SNPs of the IHRP gene were detected by the fluorescenceadapted SSCP. One of the SNPs was a new SNP resulting in an amino acid substitution, while the other SNPs have already been reported in the public databases. Six SNPs of the IHRP were associated with two haplotypes.
\end{abstract}

Conclusions: The fluorescence-adapted SSCP was useful for detecting and genotyping SNPs.

\section{Background}

Single-nucleotide polymorphisms (SNPs) are considered to be useful polymorphic markers for genetic studies of polygenic traits. A worldwide effort to collect SNPs has re- sulted in an accumulation of millions of them in the public databases. The SNPs were mainly identified by sequence determination of genomic DNA from restricted samples. 
Single-stranded conformational polymorphism (SSCP) analysis has been widely applied to detect SNPs, including point mutations in cancer and congenital diseases [1-4]. This method has been modified to detect signals by use of radio isotope-labeled PCR fragments, detection of PCR fragments by silver staining, PCR using fluorescent labeled primers, and fluorescent internal labeling of PCR fragments [5-10].

Schuelke [11] described the method using fluorescencelabeled PCR fragments for genotyping microsatellites. The procedure used the following three primers: a sequencespecific forward primer with M13 (-21) tail at its 5'-end, a sequence-specific reverse primer, and a universal fluorescent-labeled M13 (-21) primer. PCR and the labeling reactions were performed with a single tube using modified thermo-cycling conditions. In previous studies, this labeling method has been used to analyze polymorphisms of microsatellites from horses and genotyping of many microsatellites has been performed economically [12].

Inter-alpha-trypsin inhibitor family heavy chain-related protein (IHRP) is a novel 120-kDa-glycoprotein in human plasma. IHRP has homology to the heavy chains of the inter-alpha-trypsin inhibitor family (ITI) $[13,14]$. The IHRP gene spans $15 \mathrm{~kb}$, is composed of 24 exons ranging from 27 to 207 bp [15] and located to human chromosome 3p14-21 [16]. IHRP binds to actin released from the damaged cells and suppresses its toxic action by preventing the formation of actin fibril. IHRP binds to cell surface actin of polymorphonuclear (PMN) cells and inhibits their phagocytic activities. Therefore, IHRP may act as an antiinflammatory protein $[17,18]$.

In this study, we describe an application using a fluorescent-adapted primer for PCR and for SSCP analysis. The SNPs of the IHRP gene were then analyzed to identify novel SNPs that might be associated with specific diseases or be available as genetic markers for linkage analysis.

\section{Methods DNA samples}

Genomic DNA was prepared from whole blood samples collected from 20 unrelated Japanese subjects. All subjects gave their written informed consent to participate in the study and to supply blood samples for DNA analysis. Genomic DNA was extracted using MagExtractor System MFX-2000 (Toyobo, Osaka, Japan) according to the manufacture's protocols.

Table I: Primer list for SNP analysis of the IHRP gene

Forward primer

exon 01

exon 02

exon 03

exon 04

exon 05

exon 06

exon 07

exon 08

exon 09

exon 10

exon 11

exon 12

exon 13

exon 14

exon 15

exon 16

exon 17

exon 18

exon 19

exon 20

exon 21

exon 22

exon 23

exon 24

ACTAATCCATTCCCCACTTG
CATTGAAACCCTGCAACCC
ACCAGGCTCTCAACAACTC
TTGCCTTTGGCCCTTAGTCC
TCTTTGTCCCTGAGCCTCC
AACTTCAGCCCGGATTATTC
GGCCAATTGTAGCTCTGATG
CTATGTTTCCTCTCCCTGAC
CTTGAGAGTGCGTGTTCCTC
TTCTCACCCTCATCCCAAAC
AAGCCCAGCCTTTATGACAC
ATGGAAGAGCTCAGAAGTGC
CTGATGTGCTCCACCTACAG
GCAAGATTAAACACAAGCGC
CAAGATGCAAACCCAGGTC
GGCCTCAGTTCAGTTGTATC
ACCTGAGAGAAGACTGCATC
TCTGTTTCCGGATGTTCCTG
AACCCAGCCACACCTAGTC
TTGGCCCCTTTCCACATCC
GAACTCCAGGGGGTGTGAT
GACACTGGGTCTTTCCACAG
GTCTCTGACCCTTACTGATC
TTTGCTGACCACCTGCCTA

Reverse primer

TCTCTCATCCCCCAGCTC
GAGCGATGGAGTCATAGCAC
CAAGGTGGCCTTTGTCTAG
CCATCTGGAGGCAAGATGTG
CCAGAAATCCGGGCTCATAG
GTGGACAGACTTCTAGGCTG
CCACAGCTGATAGCGTGAAG
AGGGCCACAGAGACACTTA
TATTTCTGGAACCTCAGAGC
GCTTTATGACTGCCCACTTC
TTTGAGTCCAGCCCCTCTG
CTCCATGCTTAGGCGCTG
TGAGACTGCTCTTGGTCATC
CACAGCCTTTGAGGATGTTC
CAATCTGTCAATCTCCCCTC
AATAATGGACCTCCCTCAAG
TCAAGGACCACCGTGGGAA
ATCGAGACATGTGACAGGTC
AAGGATGTGGAAAGGGGCC
AGTGGTGTCTGGGTCTCTC
CTGTAGCCTGAAAGGTCAAC
AAGCACAGCTGGTTTCTGAG
GTCTGCTTGTGCCAAGTCAC
GATTTGGCCACATGGAACTG




\section{Fluorescence-adapted SSCP}

Primers for fluorescence-adapted SSCP were designed using the program DNASIS, Version 3.6 (Hitachi Software, Yokohama, Japan) based on the IHRP gene sequence (DDBJ, EMBL, and GeneBank accession numbers, NM002218), to amplify the fragments that include individual 24 exons and flanking intronic sequences. Primers were about 20 bp in length (Table 1).

An outline of the fluorescence-adapted SSCP is shown in Figure 1. In the fluorescence-adapted SSCP analysis, four primers were prepared as follows: the sequence-specific forward primer conjugated with 5'-TGA CCG GCA GCA AAA TTG-3' tail at its 5' end; the sequence-specific reverse primer conjugated with 5'-TGT AAA ACG ACG GCC AGT3 ' tail at its 5' end; the Cy-5 labeled 5'-TGA CCG GCA GCA AAA TTG-3' primer (Amersham Biosciences, NJ, USA); and the Cy-5 labeled 5'-TGT AAA ACG ACG GCC AGT-3' primer (Amersham Biosciences).

The PCR mix contained 50-100 ng of Genomic DNA, 2 pmol of the sequence-specific forward primer conjugated with 5'-TGA CCG GCA GCA AAA TTG-3', 2 pmol of the sequence-specific reverse primer conjugated with 5'-TGT AAA ACG ACG GCC AGT-3', 10 pmol of Cy-5 labeled 5'TGA CCG GCA GCA AAA TTG-3' primer, 10 pmol of Cy5 labeled 5'-TGT AAA ACG ACG GCC AGT-3' primer, 200 $\mu \mathrm{M}$ of $\mathrm{dNTP}, 2 \mu \mathrm{L}$ of $10 \times$ reaction buffer, $1 \mathrm{U}$ of rTaq polymerase (Takara Bio, Shiga, Japan) in a final $20 \mu \mathrm{L}$ reaction volume. The PCR amplification procedure entailed an initial denaturation cycle $\left(94^{\circ} \mathrm{C}, 4 \mathrm{~min}\right) ; 25$ cycles of 1 min each at $94^{\circ} \mathrm{C}, 55^{\circ} \mathrm{C}$ and $72^{\circ} \mathrm{C}$, and 10 cycles of $1 \mathrm{~min}$ each at $94^{\circ} \mathrm{C}, 50^{\circ} \mathrm{C}$ and $72^{\circ} \mathrm{C}$. This was followed by $7 \mathrm{~min}$ at $72^{\circ} \mathrm{C}$ for final extension in a GeneAmp PCR System 9600 (Applied Biosystems, CA, USA).

\section{Gel electrophoresis}

The fluorescence-labeled DNA fragments were diluted 25 times with a loading buffer consisting of formamide and EDTA (100\% formamide:50 mM EDTA = 5:1). The DNA samples were heated at $94^{\circ} \mathrm{C}$ for $5 \mathrm{~min}$ and cooled immediately on ice. This solution ( 1 to $5 \mu \mathrm{L}$ ) was applied to a non-denaturing polyacrylamide gel using $0.5 \times \mathrm{MDE}$ gel solution (BioWhittaker Molecular Applications, ME, USA) with $1 \times$ TBE buffer (100 mM Tris-borate, pH 8.3, 1 $\mathrm{mM}$ EDTA). The short gel plate was applied to the Amersham Biosciences Model ALF Express DNA sequencer. The gel temperature was strictly maintained at $15^{\circ} \mathrm{C}$. Electrophoresis was performed in $0.5 \times \mathrm{TBE}$ buffer at $30 \mathrm{~W}$ for 5 $\mathrm{h}$, and the data were collected and analyzed using Fragment Manager software (Amersham Biosciences).

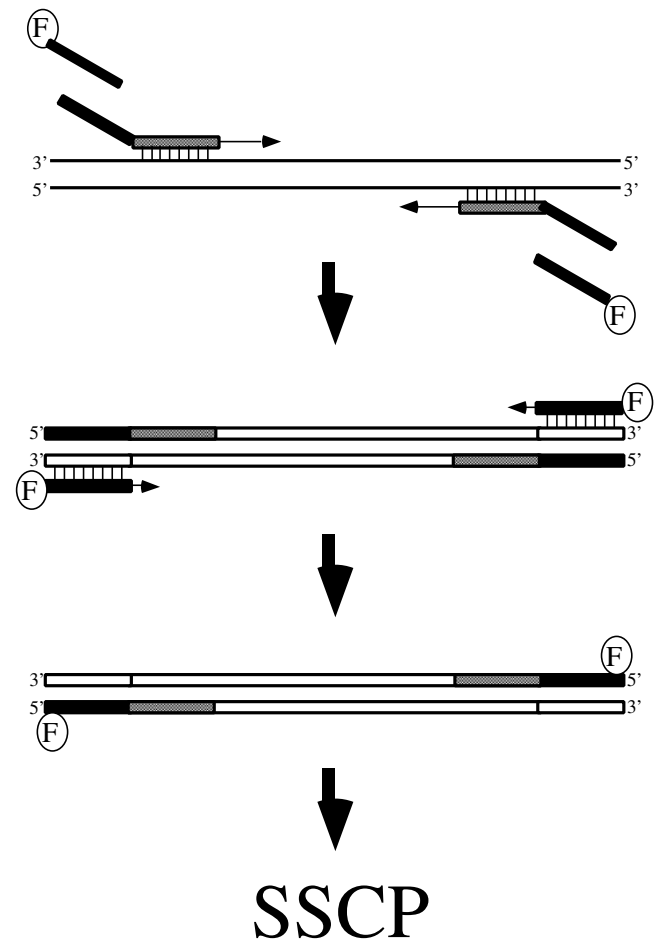

Figure I

A schematic diagram of fluorescence-adapted SSCP method. $F$ indicates a fluorescent dye (Cy-5). Shadowed boxes are specific primer sequences to amplify the IHRP gene, and black boxes are adapted sequences. These PCR reactions are performed in a single tube

\section{Direct sequencing}

DNA sequencing was done with BigDye Terminator Cycle Sequencing FS (Applied Biosystems) and determined with an ABI PRISM 377 sequencer (Applied Biosystems).

\section{Determination of allele frequencies and haplotype fre- quencies}

Allele frequencies were determined by direct counting of alleles. Haplotype frequencies in the 40 chromosomes investigated were calculated with Arlequin software (Genetic and Biometry Laboratory, Geneva, Switzerland).

\section{Results}

Effect of fluorescence-adapted SSCP

PCR fragments with the primer sets shown in Table 1 were well amplified for SSCP analysis using the fluorescenceadapted SSCP method. Figure 2 shows the migration pattern of the adapter-labeled 322-bp DNA fragments of exon 21 in the IHRP gene on non-denaturing polyacryla- 

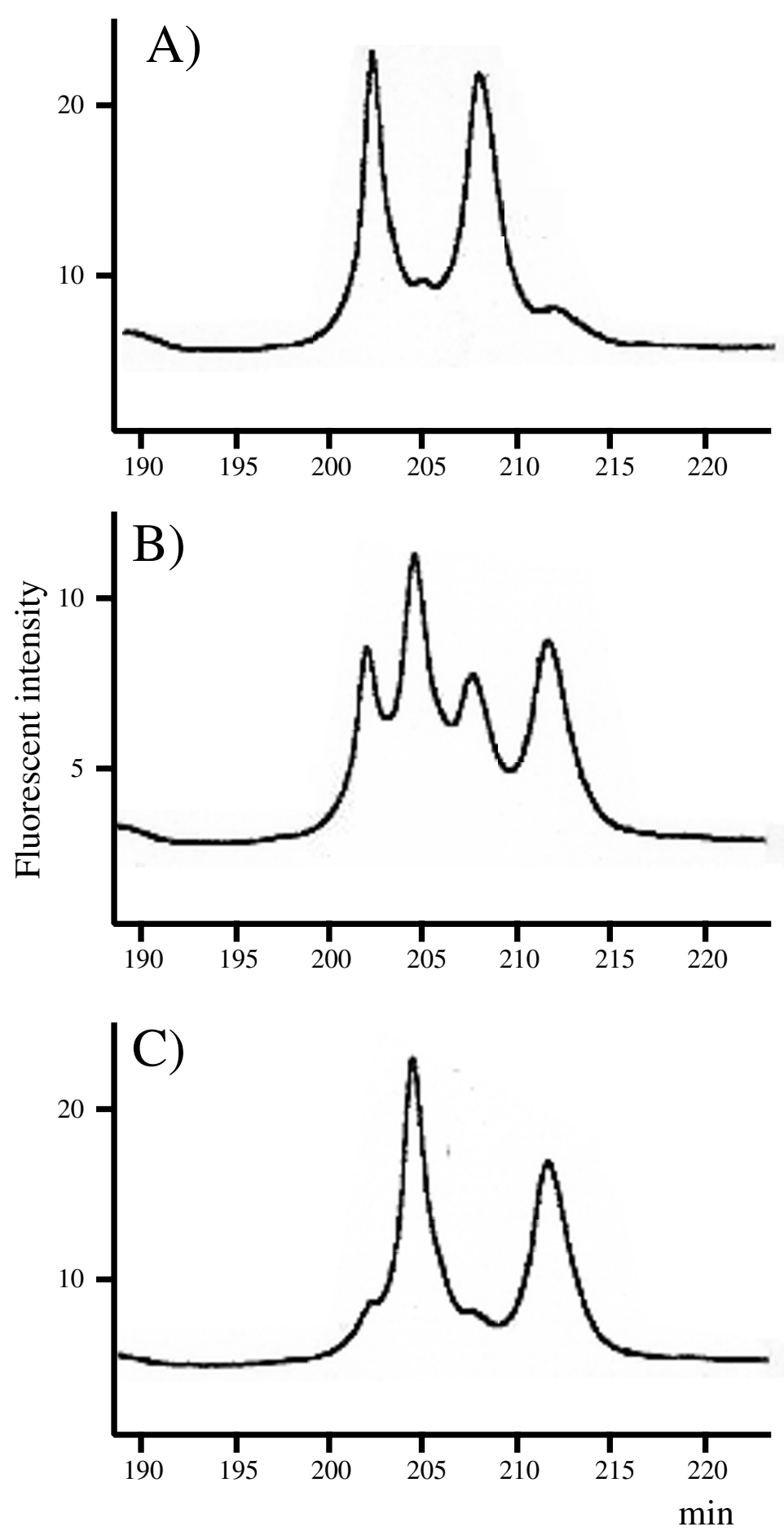

Figure 2

Electrophoretic profile on non-denaturing polyacrylamide gel of adapter-labeled 322-bp DNA fragments obtained with exon 2 I primer set of the IHRP gene. A) homo-type of main allele, B) hetero-type of main and minor alleles, C) homo-type of minor allele 


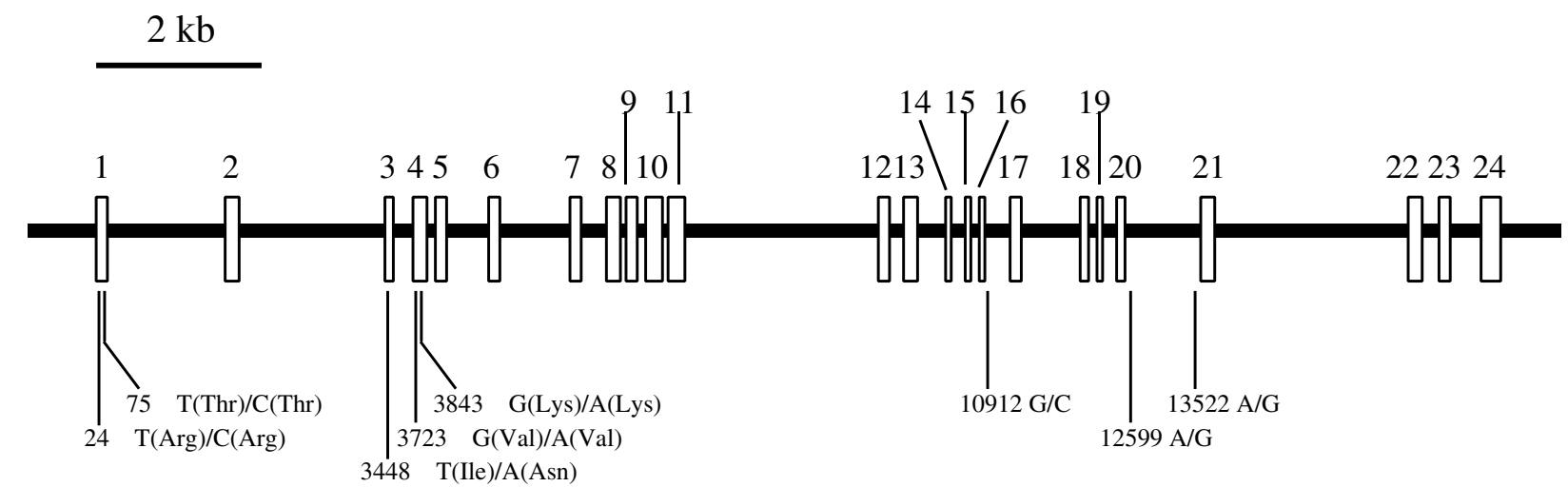

Figure 3

Relationship between genomic structure and the location of single-nucleotide polymorphisms (SNPs) in the IHRP gene

mide gel. The PCR fragments labeled with fluorescenceadapted primers were well detected on an automatic DNA sequencer. Figures $2 \mathrm{~A}, 2 \mathrm{~B}$, and $2 \mathrm{C}$ show profiles for the alleles in homozygotes (A, C) and heterozygotes (B). The alleles were clearly sequenced on non-denaturing polyacrylamide gel. The alleles were determined by direct counting.

\section{Genotyping}

A total of 20 Japanese individuals were genotyped for sequence variations of all 24 exons and the surrounding regions of the IHRP gene. A total of eight SNPs were found in the gene by this method. The locations of these SNPs are shown in Figure 3. Five of the SNPs found in the IHRP gene were located within exons: a T/C at nucleotide (nt) position 24 in exon 1, a T/C at nt position 75 in exon 1, a T/A at nt position 3448 in exon 3, a G/A at nt position 3723 in exon 4, and a G/A at nt position 3843 in exon 4. Three SNPs of the IHRP gene were located within introns: a G/C at nt position 10912 near exon 16, a A/G at nt position 12599 near exon 20, a A/G at nt position 13522 near exon 21. One of the five exon-based SNPs, the T/A at nt position 3448 in exon 3, resulted in an amino acid substitution from Ile to Asn. This is a newly identified SNP, while the remaining seven SNPs have already been reported in the NCBI dbSNP database [http://www.ncbi.nlm.nih.gov/SNP/] and the JSNP db SNP database [http://snp.ims.u-tokyo.ac.jp/]. Table 2 summarizes the SNPs and their allelic frequencies detected in our samples of 20 Japanese subjects.

\section{Allele frequencies}

Distributions of genotypes and allele frequencies among all eight polymorphisms are shown in Table 2 . The distri- butions of genotypes and allele frequencies of four SNPs at nt positions $75,3448,3723$, and 10912 were identical. The distributions of genotypes and allele frequencies of two SNPs at nt positions 12599 and 13522 were also identical. The distributions of genotypes and allele frequencies of these six SNPs were identical except for one sample. Two SNPs at nt positions 24 and 3843 showed rare alleles. Distributions of genotypes of these two SNPs were not identical to each other nor the other six SNPs.

Construction of haplotypes and calculation of their frequencies were carried out using the Arlequine algorithm. The results are summarized in Table 3. The two SNPs at nt positions 24 and 3843 were excluded from this analysis because their minor alleles were rare. Three distinct haplotypes were identified from the 20 Japanese subjects, and two of the haplotypes were more frequent than $30 \%$.

\section{Discussion}

We previously analyzed microsatellite polymorphisms using fluorescence-adapted labeling methods of PCR fragments [11] in which we designed a novel adapter sequence for the method [12]. In this study, we reported a fluorescence-adapted SSCP method, which was modified from the fluorescence-adapted labeling methods of PCR fragments, using the novel adapter sequence.

SSCP analysis is one of the simplest and most sensitive methods for detection of mutations based on PCR technology $[4,19,20]$. Since its first report, the SSCP analysis has been widely used to detect mutations in genes responsible for various hereditary diseases and somatic mutations of oncogenes. Generally, fluorescence-labeled primers are available for SSCP analysis, and SNPs are de- 
Table 2: Allele frequencies of eight SNPs of the IHRP gene

\begin{tabular}{|c|c|c|c|c|c|c|c|c|}
\hline Position*I & 24 & 75 & 3448 & 3723 & 3843 & 10912 & 12599 & 13522 \\
\hline $\begin{array}{l}\text { NCBI contig position }{ }^{* 2} \\
\text { exon/intron }\end{array}$ & $\begin{array}{l}505694 \\
\text { exon I }\end{array}$ & $\begin{array}{l}505745 \\
\text { exon I }\end{array}$ & $\begin{array}{l}509118 \\
\text { exon } 3\end{array}$ & $\begin{array}{l}509393 \\
\text { exon } 4\end{array}$ & $\begin{array}{l}509513 \\
\text { exon } 4\end{array}$ & $\begin{array}{l}516582 \\
\text { intron }\end{array}$ & $\begin{array}{l}518269 \\
\text { intron }\end{array}$ & $\begin{array}{l}519192 \\
\text { intron }\end{array}$ \\
\hline Allele (frequency \%) & $\mathrm{T}(95)$ & $\mathrm{T}(65)$ & $\mathrm{T}(65)$ & $G(65)$ & G (95) & G (65) & $A(60)$ & $A(60)$ \\
\hline \multirow[t]{3}{*}{ Amino acid } & Arg & Thr & Ile & Val & Lys & & & \\
\hline & $C(5)$ & $C(35)$ & $A(35)$ & $A(35)$ & $A(5)$ & $C(35)$ & $\mathrm{G}(40)$ & G (40) \\
\hline & Arg & Thr & Asn & Val & Lys & & & \\
\hline
\end{tabular}

*I The positions were counted from the ATG initiation codon of the IHRP gene. *2The NCBI contigs were derived from assembled genomic sequence data of locus NT_005986.

Table 3: Haplotype frequencies of six SNPs of the IHRP gene

\begin{tabular}{lcccccccc}
\hline Position & 75 & 3448 & 3723 & 10912 & 12599 & 13522 & Frequencies \\
\hline haplotype-1 & T & T & G & G & A & A & $60 \%$ & $30 \%$ \\
haplotype-2 & C & A & A & C & G & G & $10 \%$ \\
haplotype-3 & T & T & G & G & G & G & \\
\hline
\end{tabular}

tected with fluorescence-detecting automatic DNA sequencers, such as ALF Express, ABI377 and ABI3100. However, the fluorescence-labeled primers are expensive. In order to detect all SNPs of a gene region, it is necessary to design and synthesize fluorescence-labeled primer sets for about every $400 \mathrm{bp}$, or the size of an exon. Recently, some SSCP methods using internal fluorescent labeling of PCR fragments were reported $[7,8]$. Although these methods carried out the labeling reaction using a single tube, the procedures of those methods were complicated because of the requirement to use enzymes and buffers after PCR for the labeling reaction. Our method, the fluorescence-adapted SSCP method, is a simple and efficient method for detection of SNPs because the method only modifies the PCR conditions using fluorescence-adapted primers and the specific primers used with the adapted sequences. Our results were identical to results obtained using fluorescence-labeled primer (data not shown). Only the retention times of detected alleles on non-denaturing polyacrylamide gel between those methods were different. The retention time might be influenced by the adapted sequences. Although our method showed longer retention times compared to SSCP methods using fluorescence-adapted primers, the migration pattern was almost coincident. This phenomenon was observed in analyzing microsatellite polymorphisms [12]. Thus, it is indicated that the adapted sequences were not influenced by SSCP analysis, nor were non-labeled PCR products. Those results proved that the fluorescence-adapted SSCP method is one of the simplest and most useful methods for SSCP.

In this method, we used two adapted sequences: 5'-TGA CCG GCA GCA AAA TTG-3' from M13 (-21) and 5'-TGT AAA ACG ACG GCC AGT-3', originally designed in a previous study. It is necessary to prepare different thermo-cycling conditions for the cycle sequencing reaction when specific sequence primers are used for SSCP analysis. The adapter sequences are available as primers for direct sequencing to determine nucleotide sequences of SNPs with the same thermo-cycling condition. Although we used one fluorescent dye in this study, (Cy-5, with ALF express DNA sequencer), allele peaks of multi-fluorescent color could be detected by using different fluorescent dyeadapted primers, resulting in determination of nucleotide sequences of alleles for SNPs.

Recently, Inazuka et al. (1996; 1997) [6,8] developed a streamlined and cost-effective mutation/polymorphism detection method (PLACE-SSCP) in which PCR products are post-labeled with fluorescent dyes, and analyzed with an automated capillary electrophoresis system under SSCP conditions. Sasaki et al. (2001) [21] reported a precise estimation of allele frequencies of SNPs by PLACESSCP analysis of pooled DNA, and the methods showed 
allele frequencies accurately estimated by pooling DNA samples. Peak heights of alleles amplified from the same amount of genomic DNA by the fluorescence-adapted SSCP were coincident, as shown in Figure 1. The results suggested that allele frequencies accurately estimated from pooling DNA samples using fluorescence-labeled primers are identical to allele frequencies estimated from the individual DNAs.

In this study, we detected eight SNPs of the IHRP gene using the method described. Although seven SNPs were reported in the NCBI dbSNP database [http:// www.ncbi.nlm.nih.gov/SNP// and the JSNP db SNP database [http://snp.ims.u-tokyo.ac.jp/], one novel SNP, which had an amino acid substitution, was identified. Those results indicated that our method is as sensitive and accurate as SSCP methods previously reported and is useful for detection and genotyping methods of SNPs.

We detected a novel SNP that showed an amino acid substitution from Ile to Asn. In pig and mouse IHRP genes, this residue is conserved as Ile. The amino acid substitution to Asn might occur in humans or primates. The SNP converted the Sau3AI site from GATC to GAAC: thus the SNP could be detected using PCR-RFLP. Because the SNP has strong linkage disequiriburium with the other five SNPs at nt positions 75, 3723, 10912, 12599, and 13522, the six SNPs were considered to be one locus. Thus, the novel SNP is useful as a genetic marker of the IHRP gene region with PCR-RFLP, because PCR-RFLP is one of the simple methods using conventional restriction enzyme and agarose-electrophoresis.

\section{Competing interests}

None declared.

\section{Authors' Contributions}

TT carried out the molecular genetic studies and drafted the manuscript. NHCM and MT obtained and administrated the blood samples. MK helped in setting up the technique. NHCM and MT participated in its design and coordination.

All authors have read and approved the final manuscript.

\section{Acknowledgements}

We thank Dr S. Mashima of Laboratory of Racing Chemistry for helpful discussion and suggestions. This work was supported in part by the HighTechnology Research Center Project from the Ministry of Education, Science, Sports and Culture of Japan.

\section{References}

I. Orita M, Iwahana H, Kanazawa H, Hayashi K, Sekiya T: Detection of polymorphisms of human DNA by gel electrophoresis as single-strand conformation polymorphisms. Proc Natl Acad Sci U S A 1989, 86:2766-2770

2. Suzuki Y, Orita M, Shiraishi M, Hayashi K, Sekiya T: Detection of ras gene mutations in human lung cancers by single-strand con- formation polymorphism analysis of polymerase chain reaction products. Oncogene 1990, 5:1037-1043

3. Suzuki Y, Sekiya T, Hayashi K: Allele-specific polymerase chain reaction: a method for amplification and sequence determination of a single component among a mixture of sequence variants. Anal Biochem I99I, 1 92:82-84

4. Hayashi K: PCR-SSCP: A method for detection of mutations. Genet Anal Tech Appl 1992, 9:73-79

5. Makino R, Yazyu H, Kishimoto Y, Sekiya T, Hayashi K: F-SSCP: fluorescence-based polymerase chain reaction-single-strand conformation polymorphism (PCR-SSCP) analysis. PCR Methods Appl 1992, 2:10-13

6. Inazuka M, Tahira T, Hayashi K: One-tube post-PCR fluorescent labeling of DNA fragments. Genome Res 1996, 6:55 I-557

7. Iwahana H, Fujimura M, Takahashi Y, Iwabuchi T, Yoshimoto K, Itakura M: Multiple fluorescence-based PCR-SSCP analysis using internal fluorescent labeling of PCR products. Biotechniques 1996, $21: 510-519$

8. Inazuka M, Wenz HM, Sakabe M, Tahira T, Hayashi K: A streamlined mutation detection system: multicolor post-PCR fluorescence labeling and single-strand conformational polymorphism analysis by capillary electrophoresis. Genome Res 1997, 7: 1094-1103

9. Chiarelli I, Porfirio B, Mattiuz PL, Seri M, Caroli F, Celli I, Romeo G, Volorio S, Zollo M: A method for point mutation analysis that links SSCP and dye primer fluorescent sequencing. Mol Cell Probes 1998, 12:125-131

10. Esposito DL, Palmirotta R, Veri MC, Mammarella S, D'Amico F, Curia MC, Aceto G, Crognale S, Creati B, Mariani-Costantini R, Battista P, Cama A: Optimized PCR labeling in mutational and microsatellite analysis. Clin Chem 1998, 44: /38|-1387

II. Schuelke M: An economic method for the fluorescent labeling of PCR fragments. Nat Biotechnol 2000, 18:233-234

12. Tozaki T, Mashima S, Hirota K, Miura N, Choi-Miura NH, Tomita M: Characterization of equine microsatellites and microsatellite-linked repetitive elements (eMLREs) by efficient cloning and genotyping methods. DNA Res 200I, 8:33-45

13. Choi-Miura NH, Sano Y, Oda E, Nakano Y, Tobe T, Yanagishita T, Taniyama M, Katagiri T, Tomita M: Purification and characterization of a novel glycoprotein which has significant homology to heavy chains of inter-alpha-trypsin inhibitor family from human plasma. I Biochem (Tokyo) 1995, I I 7:400-407

14. Saguchi K, Tobe T, Hashimoto K, Sano Y, Nakano Y, Miura NH, Tomita $\mathrm{M}$ : Cloning and characterization of cDNA for inter-alphatrypsin inhibitor family heavy chain-related protein (IHRP), a novel human plasma glycoprotein. J Biochem (Tokyo) 1995, I 17:14-18

15. Saguchi K, Tobe T, Hashimoto K, Nagasaki Y, Oda E, Nakano Y, Miura $\mathrm{NH}$, Tomita M: Isolation and characterization of the human inter-alpha-trypsin inhibitor family heavy chain-related protein (IHRP) gene (ITIHLI). J Biochem (Tokyo) 1996, I I 9:898-905

16. Tobe T, Saguchi K, Hashimoto K, Miura NH, Tomita M, Li F, Wang Y, Minoshima S, Shimizu N: Mapping of human inter-alpha-trypsin inhibitor family heavy chain-related protein gene (ITIHLI) to human chromosome 3p2I $\rightarrow$ | I4. Cytogenet Cell Genet 1995, 7I:296-298

17. Choi-Miura NH, Takahashi K, Yoda M, Saito K, Hori M, Ozaki H, Mazda T, Tomita M: The novel acute phase protein, IHRP, inhibits actin polymerization and phagocytosis of polymorphonuclear cells. Inflamm Res 2000, 49:305-310

18. Choi-Miura NH: Quantitative measurement of the novel human plasma protein, IHRP, by sandwich ELISA. Biol Pharm Bull 200I, 24:214-2I7

19. Hayashi K, Yandell DW: How sensitive is PCR-SSCP? Hum Mutat 1993, 2:338-346

20. Hayashi K: Recent enhancements in SSCP. Genet Anal 1999, 14:193-196

21. Sasaki T, Tahira T, Suzuki A, Higasa K, Kukita Y, Baba S, Hayashi K: Precise estimation of allele frequencies of single-nucleotide polymorphisms by a quantitative SSCP analysis of pooled DNA. Am J Hum Genet 200I, 68:214-218

\section{Pre-publication history}

The pre-publication history for this paper can be accessed here: 
http://www.biomedcentral.com/1471-2350/3/6/prepub

Publish with BioMed Central and every scientist can read your work free of charge

"BioMedcentral will be the most significant development for disseminating the results of biomedical research in our lifetime." Paul Nurse, Director-General, Imperial Cancer Research Fund

Publish with BMC and your research papers will be:

- available free of charge to the entire biomedical community

- peer reviewed and published immediately upon acceptance

- cited in PubMed and archived on PubMed Central

- yours - you keep the copyright

Submit your manuscript here:

http://www.biomedcentral.com/manuscript/
BioMedcentral com editorial@biomedcentral.com 